\section{Vasculitis asociadas a anticuerpos anti-citoplasma de neutrófilos: avances en patogenia y tratamiento}

\author{
FRANCISCO SILVA, MARCELA CISTERNAS
}

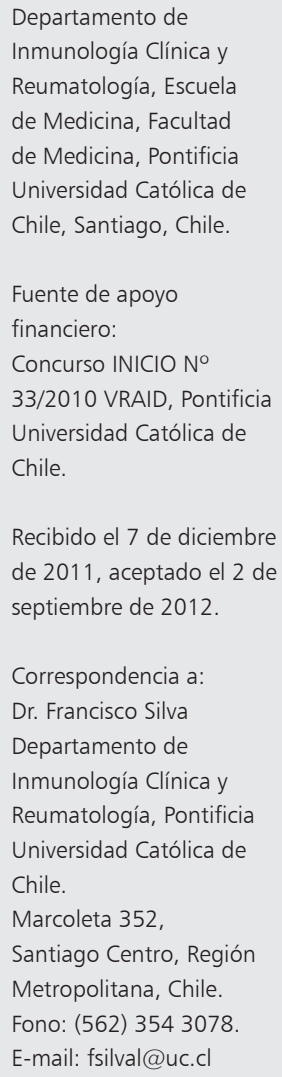

\begin{abstract}
ANCA (anti-neutrophil cytoplasmic antibodies) associated vasculitis or AAV are
group of diseases with predominant inflammation of small vessels and the presence of detectable ANCA in serum. Due to these common features, it is considered that $A A V$ share pathogenic mechanisms. Consequently, a similar therapeutic approach
has been developed. A new nomenclature has been recently proposed, with AAV including "granulomatosis with polyangiitis" (GPA, formerly Wegener's granulomatosis), "microscopic polyangiitis" (MPA), "eosinophilic granulomatosis with polyangiitis" (EGPA, formerly Churg-Strauss disease) and renal limited vasculitis. Research on $A A V$ has shown significant advances in the last two decades, including advances in the knowledge of pathogenic mechanisms such as the pro-inflammatory role of ANCA, AAV murine models and genetic links. Evidence on previous immunosuppressive therapies has improved significantly and new, promissory drugs have been introduced, Rituximab being the most important. We review the advances of pathogenic mechanisms and treatment for these diseases.
\end{abstract}

(Rev Med Chile 2013; 141: 765-773).

Key words: Churg-Strauss syndrome; Vasculitis, Wegener granulomatosis.
L a frecuente presencia de los anticuerpos anti-citoplasma de neutrófilos (ANCA) y el compromiso inflamatorio de la pared de vasos pequeños en múltiples órganos son las características centrales del grupo de vasculitis asociadas a ANCA (VAA). Recientemente su nomenclatura ha sido actualizada", e incluye a la "granulomatosis con poliangiitis" (GPA, previamente granulomatosis de Wegener), la poliangiitis microscópica (MPA), la "eosinofilia y granulomatosis con poliangiitis" (EGPA, previamente enfermedad de Churg-Strauss) y la vasculitis limitada a riñón. El presentar características serológicas e histológicas comunes, ha llevado a considerar que tienen una patogenia compartida, por lo que se han planteado estrategias terapéuticas similares.

La investigación y el conocimiento sobre estas vasculitis han alcanzado grandes avances en las últimas dos décadas, debido principalmente al trabajo de grupos colaborativos de los Estados Unidos de Norteamérica (VCRC) ${ }^{3}$ y europeos (EUVAS y GFEV $)^{4,5}$. Así, hoy contamos con sólidos estudios prospectivos, como el CYCAZAREM, NORAM, MEPEX, RAVE, RITUXVAS y otros (definición de acrónimos en Tabla 1), que han permitido establecer pautas de consenso internacionales para el manejo de estas patologías.

En este artículo se presenta una actualización de conceptos sobre la patogenia y el tratamiento de las VAA.

\section{Patogenia}

La etiología de las vasculitis VAA es desconocida y la investigación sobre su patogenia se centra en el propio papel de los ANCA. La sola 
presencia de estos auto-anticuerpos implica pérdida de tolerancia, déficits de regulación y participación de linfocitos $\mathrm{T}$ y $\mathrm{B}$ en su producción. Múltiple evidencia in vitro e in vivo apoya el papel patogénico de ANCA y del neutrófilo ${ }^{6-11}$. En esta sección se presentan algunos aspectos del modelo patogénico, con foco en aquellos con implicancia terapéutica (Figura 1 ).

Tabla 1. Ensayos multicéntricos incluidos en la presente revisión

\begin{tabular}{|c|c|c|c|}
\hline Acrónimo & Título corto del ensayo & Año & Ref \\
\hline \multicolumn{4}{|l|}{ Inducción } \\
\hline CYCLOPS & CYclophosphamide Daily Oral Versus PulSed & 2009 & [29] \\
\hline NORAM & NOn-Renal Wegener's granulomatosis treated Alternatively with Methotrexate & 2005 & [31] \\
\hline RAVE & Rituximab for ANCA-Associated Vasculitis & 2010 & [33] \\
\hline RITUXVAS & RITUXimab vs cyclophosphamide for ANCA-associated renal VASculitis & 2010 & [34] \\
\hline MEPEX & MEthyl prednisolone or $\mathbf{P l a s m a ~} \mathbf{E X}$ change for severe renal vasculitis & 2007 & [35] \\
\hline \multicolumn{4}{|l|}{ Mantención } \\
\hline CYCAZAREM & CYclophosphamide vs AZAthioprine for REMission in generalised vasculitis & 2003 & [39] \\
\hline IMPROVE & International MycoPhenolate mofetil to Reduce $\mathbf{O}$ (utbreaks of $\mathbf{V}$ asculitides & 2010 & [44] \\
\hline MAINRITSAN & MAINtenance RITuximab after Remission In Systemic ANCA-associated vasc. & curso & \\
\hline
\end{tabular}

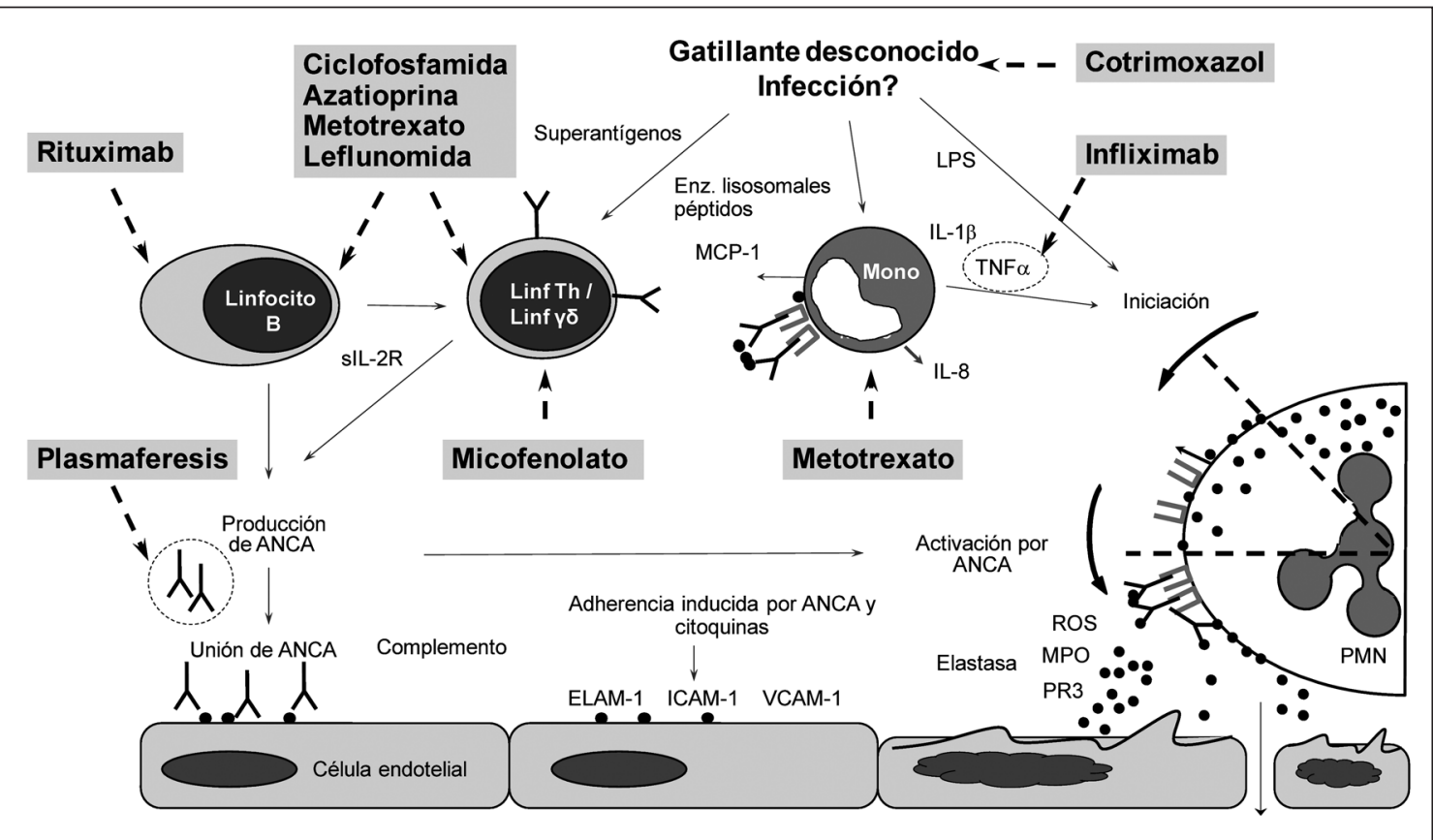

Figura 1. Patogenia de la Vasculitis asociadas a ANCA y mecanismos frecuentemente aceptados de acción de fármacos. Notas: La mayoría de la evidencia proviene de estudios en Granulomatosis con Poliangiitis (GPA, ex E. de Wegener). Flechas

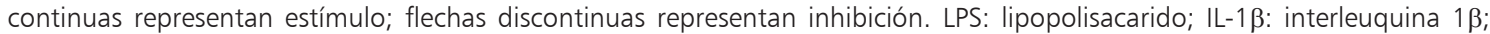
MCP-1: proteína quimiotáctica de monocitos 1; TNF $\alpha$ : factor de necrosis tumoral alfa; ANCA: anticuerpos anti citoplasma de neutrofilos; ELAM-1: selectina E; ICAM-1: molécula de adhesión intercelular 1; VCAM-1: molécula de adhesión celular vascular; ROS; agentes oxidantes; MPO: mieloperoxidasa; PR3: proteinasa 3; PMN: polimorfonuclear. 


\section{Papel de las infecciones}

La infección es una de las condiciones clínicas que determina mayor liberación de citoquinas y activación celular, pudiendo gatillar los primeros eventos de una vasculitis. Los pacientes con vasculitis activa presentan niveles elevados de factor de necrosis tumoral alfa (TNF $\alpha$ ) y sobreexpresión de antígenos de ANCA en la superficie de los neutrófilos, permitiendo la interacción con los ANCA circulantes. Esta interacción, incrementaría los efectos pro-inflamatorios del anticuerpo, con perpetuación de la cascada inflamatoria sobre el endotelio. Se ha descrito la presencia de ANCA en pacientes con algunas infecciones y sin vasculitis clínica, que desaparecerían en relación al tratamiento antimicrobiano ${ }^{12}$. En GPA, las infecciones pueden inducir recaídas y estas aumentan en pacientes portadores nasales de estafilococo dorado $^{13}$. Lo anterior sugiere que los ANCA podrían ocurrir transitoriamente en el contexto de una infección, y que la persistencia de la respuesta de los ANCA en pacientes con vasculitis pudiera ser el resultado de un mimetismo molecular con antígenos presentes en las infecciones.

\section{Generación de ANCA: modelos animales}

Los modelos murinos confirman la generación de ANCA post inmunización con mieloperoxidasa (MPO) con desarrollo de vasculitis ${ }^{14,15}$. Ratones MPO-/-, después de ser inmunizados con MPO, generan anticuerpos de alta avidez ${ }^{15}$. La transferencia de esplenocitos de esos animales a ratones Rag-/-, o de IgG conteniendo anticuerpos antiMPO a ratones normales, desarrolla una glomerulonefritis necrotizante y crescéntica, inflamación granulomatosa y vasculitis necrotizante sistémica. El agregar lipopolisacárido aumenta la injuria renal y los niveles de TNF $\alpha$; y la intensidad de la injuria es reducida por anticuerpos anti-TNFa. La presencia de una significativa infiltración de neutrófilos en las lesiones confirma el papel central de esas células en la patogenia de la enfermedad ${ }^{16}$.

\section{Generación ANCA: papel de los linfocitos}

La importancia de los linfocitos B es obvia si se considera su papel como células productoras de anticuerpos, y por tanto, de ANCA. Evidencia directa de su participación incluye el que las células B son encontradas en los tejidos afectados por la GPA, por ej., en el infiltrado intersticial de glomerulonefritis o en lesiones nasales ${ }^{17}$ y que la proporción de células B circulantes esta aumen- tada en pacientes con GPA activa comparada con enfermedad en remisión o controles sanos ${ }^{18}$.

\section{Mecanismos patogénicos de los ANCA}

\section{Evidencia de patogenicidad}

Recientemente un modelo murino fue generado inyectando células troncales irradiadas en ratón $\mathrm{NOD}$-scid-IL2R $\gamma^{-1}$. En este ratón quimérico, se comparó el efecto de infundir IgG humana de pacientes PR3-ANCA (+) con la de controles con glomerulonefritis no vasculítica o voluntarios sanos. Los ratones IgG PR3-ANCA (+) desarrollaron hematuria, GNF proliferativa pauciimmune y vasculitis hemorrágica en pulmones; ninguno de estos hallazgos aparecieron en los controles. Esta evidencia apoya la patogenicidad de IgG de pacientes GPA PR3-ANCA $(+)^{19}$.

\section{Efectos derivados de la interacción ANCA-neutrófilo}

Como parte de la respuesta inmune normal, la estimulación del neutrófilo por citoquinas (TNFa, IL1, IL6, IL18) lleva a degranulación y a presentación de componentes en la superficie celular paso necesario para que los ANCA se constituyan en patogénicos, a través de la activación del neutrófilo ${ }^{20}$. Además se ha reconocido la expresión constitutiva ( sin estímulo) de PR3, en una fracción fija de neutrófilos circulantes, lo que está genéticamente determinado, es estable en el tiempo y es una característica no observada en otros componentes de los gránulos azurófilos ${ }^{21,22}$. Así, la interacción de los ANCA con los neutrófilos puede ocurrir a través de los antígenos presentados en la membrana del neutrófilo (principalmente PR3) mediante la porción Fab'2, y por la unión del fragmento Fc del ANCA con receptores Fc en la superficie celular. Esta interacción induce la cascada respiratoria ${ }^{23}$. A nivel intracelular, los ANCA desencadenan la inducción de múltiples vías ${ }^{24}$ : proteína $\mathrm{G}$ y GTPasa (a través de fragmento Fab $)^{25}$ y tirosina quinasas (a través del receptor $\mathrm{Fc})^{26}$, que convergen en la GTPasa p21 ${ }^{\text {RAS }}$, molécula que participa en muchos procesos celulares del neutrófilo, incluyendo la activación respiratoria. Se ha demostrado cambios en la expresión genética que reflejan la actividad de la enfermedad en vivo ${ }^{27}$.

\section{Facilitación de la adhesión neutrófilo-endotelio por ANCA}

Los neutrófilos expuestos a ANCA se adhieren a células endoteliales activadas con TNF $\alpha$ a través 
de moléculas de adhesión, tales como $\mathrm{CD} 11 \mathrm{~b}^{28}$. Esta adherencia ha sido estudiada en modelos de flujo capilar, donde se ha demostrado que pretratar neutrófilos con ANCA induce estabilidad de la adhesión e incremento en la transmigración ${ }^{29}$.

El daño endotelial, manifestado como necrosis fibrinoide, permite la exposición de la membrana basal, con adherencia plaquetaria, trombosis y oclusión de vasos. La sobre-expresión de moléculas de adhesión y la liberación de proteínas quimo-atrayentes desde la célula endotelial probablemente promueve la adhesión y transmigración de leucocitos, contribuyendo aún más al daño endotelial.

\section{Manifestación de las vasculitis en órganos}

Las VAA presentan a nivel tisular dos tipos de lesiones que condicionan su expresión clínica: inflamación de la pared vascular o granulomas ${ }^{30}$. La primera se observa en todas las formas, mientras que la segunda es predominante en GPA y EGPA. Si bien ambas lesiones pueden observarse concomitantemente en biopsias, es el compromiso de la pared de vasos el que explica manifestaciones como la hemorragia alveolar y la glomerulonefritis, mientras que los granulomas predominan en los nódulos pulmonares, estenosis subglótica y tumor retro-orbitario. El modelo actual de patogenia basado en ANCA explica grandemente el compromiso vascular pero no el desarrollo de granulomas. Mayor estudio de las múltiples tipos celulares que conforman el granuloma y de su interacción son necesarios ${ }^{30}$.

\section{Tratamiento}

\section{Estadios de la enfermedad}

Para sistematizar el tratamiento, las manifestaciones de las VAA se han clasificado, de acuerdo al grado de compromiso clínico, en localizadas, con síntomas restringidos a la vía aérea superior y/o inferior, y sistémicas, precoces o tardías. La forma sistémica precoz está definida como una forma de vasculitis limitada a un órgano, con síntomas constitucionales, creatinina menor de $1,7 \mathrm{mg} / \mathrm{dl}$ si hay compromiso renal, $\mathrm{paO}_{2}$ mayor de $70 \%$, o capacidad de difusión de monóxido mayor de $70 \%$, en caso de compromiso pulmonar. La forma sistémica tardía está definida por un compromiso de órganos vitales grave ${ }^{31}$.

\section{Tratamientos para inducción de remisión}

Ciclofosfamida. Es reconocido que la ciclofosfamida, junto con los corticoides, es el principal pilar en la inducción de remisión de las vasculitis. La introducción en la década 1970-79 de esta terapia combinada, mejoró sustancialmente el pronóstico de los pacientes. Sin embargo, su uso aún plantea problemas: alta tasa de efectos adversos, falta de respuesta en $10 \%$ de los pacientes y tasa de recaídas de hasta $50 \%{ }^{32}$.

El estudio CYCLOPS (2009) ${ }^{33}$ incluyó 149 pacientes, de 15 países, y comparó la eficacia de ciclofosfamida oral $(2 \mathrm{mg} / \mathrm{kg}$ ) diaria vs endovenosa ( $15 \mathrm{mg} / \mathrm{kg}$ ) administrados cada dos semanas los primeros tres pulsos, y luego cada tres semanas hasta completar 10 pulsos. Ambos grupos recibieron corticoides desde el comienzo y azatioprina una vez obtenida la remisión. No hubo diferencias en la tasa de remisión o recaídas, ni en la duración de tratamiento para alcanzar remisión. Las dosis acumuladas de ciclofosfamida fueron menores en la forma endovenosa $(8,2$ vs 15,9 g; $p<0,001)$ así como las tasas de leucopenia.

Desde los primeros reportes sobre el uso de ciclofosfamida por Hoffman y cols., se reconoció que su uso prolongado se asocia a riesgo aumentado de toxicidad, principalmente infecciones, cistitis hemorrágica y cáncer de vejiga ${ }^{34}$. Recientemente, un estudio de cohorte de 805 pacientes con AAV, demostró que la dosis acumulada de ciclofosfamida era un predictor independiente de cáncer del tracto urinario y/o cistitis hemorrági$\mathrm{ca}^{35}$. La toxicidad de la ciclofosfamida ha motivado la búsqueda de drogas efectivas que, teniendo mecanismos de acción más específicos, permitan reducir el perfil de riesgo ${ }^{35}$.

Metotrexato. Esta droga ha sido principalmente estudiada para tratar formas menos graves de vasculitis (localizadas y sistémicas precoces). Las primeras publicaciones que demostraron su beneficio en inducción de remisión de GPA, datan de hace 40 años. Luego el primer estudio abierto fue realizado por el NIH en $1992^{36}$ con 29 pacientes utilizando $20-25 \mathrm{mg}$ semanal de metotrexato más corticoides. Alcanzada la remisión por un año, se disminuyó la dosis en 2,5 mg mensual. Al momento del ingreso, 12/29 pacientes tenían un sedimento de orina activo, y 6 de ellos creatinina entre 1,5 y $2,8 \mathrm{mg} / \mathrm{dl}$, lográndose remisión completa en $22 / 29$ pacientes (69\%). Nueve pacientes 
experimentaron efectos adversos: neumonitis por metotrexato en 2 y neumonía por Pneumocystis jiroveci en 3.

Otros estudios abiertos con metotrexato fueron publicados posteriormente, siempre en pacientes con vasculitis localizada y/o en forma sistémica precoz. Las tasas de remisión completas variaron entre 71 y $90 \%$, sin embargo, se incluyeron pacientes con debut de la enfermedad, recaídas o fallas a tratamiento convencional, por lo que no son comparables.

El primer estudio aleatorizado con metotrexato es el NORAM (2005), que demostró que este medicamento no era inferior a la ciclofosfamida en la inducción de remisión de pacientes con formas localizadas o sistémicas precoces ${ }^{37}$. Cincuenta pacientes con VAA recién diagnosticadas, creatinina menor de $1,8 \mathrm{mg} / \mathrm{dl}$ y sin compromiso crítico de órganos fueron asignados a recibir metotrexato oral $20-25 \mathrm{mg}$ semanal vs 50 pacientes que recibieron ciclofosfamida oral, $2 \mathrm{mg} / \mathrm{kg} / \mathrm{día}$, por 12 meses. Las tasas de remisión y efectos adversos fueron similares $(89,9 \%$ vs $93,5 \%)$.

Rituximab. El primer estudio retrospectivo con un significativo número de casos de vasculitis tratadas con rituximab fue publicado el año $2009^{38}$. Incluía 65 pacientes, con esquema de 4 infusiones de $375 \mathrm{mg} / \mathrm{m}^{2}$ semanal o dos infusiones de $1 \mathrm{~g}$ cada una, separadas por dos semanas. Se observó remisión total en $75 \%$ y parcial en $23 \%$. Más de la mitad de los pacientes presentó recaída posterior y posterior a retratamiento con rituximab, hubo remisión completa en más de $80 \%$.

Recientemente dos estudios aleatorizados con rituximab para inducción de remisión, fueron publicados en forma simultánea. El primero de ellos, RAVE (2010) ${ }^{39}$, comparó ciclofosfamida oral ( $2 \mathrm{mg} / \mathrm{kg} /$ día) versus 4 pulsos de rituximab semanales de $375 \mathrm{mg} / \mathrm{m}^{2}$, en 197 pacientes con VAA con creatinina menor a $4 \mathrm{mg} / \mathrm{dl}$ (80\% GPA y $20 \%$ MPA), debutando con la enfermedad o en recaída. Todos recibieron $3 \mathrm{~g}$ de metilprednisolona y luego prednisona con disminución gradual en 6 meses. Conseguida la remisión, el grupo tratado con ciclofosfamida recibió azatioprina, mientras que el grupo tratado con rituximab recibió placebo. No se observó diferencias significativas en conseguir remisión (índice de actividad BVAS-WG $=0$ y $\sin$ corticoides a 6 meses), tasas de recaídas o efectos adversos.
El segundo de los estudios, RITUXVAS $(2010)^{40}$ comparó la eficacia de 4 pulsos semanales de rituximab de $375 \mathrm{mg} / \mathrm{m}^{2}$, asociado a 2 pulsos de ciclofosfamida vs pulsos de ciclofosfamida por 3 a 6 meses. Se estudiaron 44 pacientes debutando con vasculitis, todos recibieron corticoides hasta por 12 meses. Tampoco hubo diferencias en la remisión, muertes, recuperación de función renal, efectos adversos serios o dosis acumulada de corticoides. Es de notar que la mortalidad observada en el grupo RITUXVAS fue de $18 \%$, vs de 1,5\% en el RAVE, lo que podría estar dado por el hecho de combinar ciclofosfamida con rituximab o bien porque los pacientes con hemorragia alveolar o falla renal con creatinina mayor de 4 fueron excluidos en el RAVE e incluidos en el RITUXVAS.

A pesar que en forma global no hay diferencia significativa entre ciclofosfamida y rituximab para inducir remisión, en el RAVE se observó que en pacientes enrolados por recaída de la enfermedad, rituximab fue más eficaz en conseguir remisión que la ciclofosfamida.

Plasmaféresis. Su uso en inducción de remisión de vasculitis es controversial aún. El estudio $\operatorname{MEPEX}(2007)^{41}$, comparó el uso de siete sesiones de plasmaféresis vs 3 pulsos de metilprednisolona agregados a tratamiento convencional (ciclofosfamida oral y prednisolona oral), en pacientes con falla renal y creatinina mayor a $5,8 \mathrm{mg} / \mathrm{dl}$. El estudio demostró una mejor preservación de la función renal en los pacientes con plasmaféresis a 3 meses y reducción de diálisis a 1 año. Sin embargo, la sobrevida a 12 meses fue similar comparando plasmaféresis vs metilprednisolona (76\% vs $73 \%)$.

Drogas anti-TNF. A pesar que evidencia experimental sustentaba su uso, el estudio WGET con etanercept ${ }^{42}$ no demostró eficacia. Este estudio evaluó aleatoriamente etanercept versus placebo agregado a terapia estándar en 180 pacientes con GPA. Además, el grupo tratado con etanercept tuvo una significativa mayor incidencia de tumores sólidos, desalentando el uso de esta familia de drogas $^{43}$. Sin embargo, posteriormente, un estudio prospectivo no controlado, con infliximab demostró acortamiento del período necesario para conseguir remisión, con reducción de la dosis 
acumulada de corticoides ${ }^{44}$. Varios reportes de casos, confirman esta observación, sin evidenciar un incremento en la tasa de cánceres. Estas diferencias entre dos anti-TNF pueden deberse a la combinación utilizada etanercept-ciclofosfamida, o a diferencias intrínsecas entre ambas las drogas (receptor soluble versus anticuerpos).

\section{Mantención de remisión}

Para evitar los efectos adversos del uso prolongado de ciclofosfamida, se prefieren otras drogas para la mantención de remisión. Las alternativas incluyen: azatioprina, metotrexato, leflunomida y micofenolato. No hay estudios comparativos, de cuatro ramas, para determinar la eficacia comparativa.

Azatioprina. En el CYCAZAREM (2003) ${ }^{45}$, una vez obtenida la remisión, los pacientes fueron asignados a continuar con ciclofosfamida $(n=73)$ o azatioprina $(n=71)$, sin diferencias significativas en las tasas de recaída.

Metotrexato. Los primeros estudios abiertos con esta droga demostraron tasas de recaídas de $10 \%$, con muy baja frecuencia de efectos adversos, significativamente menores que con cotrimoxazol (tasa de recaída mayor a $50 \%)^{46}$.

Otros estudios mostraron tasas de recaída con metotrexato similares a la ciclofosfamida ${ }^{47}$. El estudio NORAM demostró tasas de recaída a 18 meses mayores para el grupo metotrexato que el grupo ciclofosfamida ( $70 \%$ vs $47 \%$ ).

Un estudio abierto aleatorizado del grupo GFEV $(2008)^{48}$, comparó azatioprina $(2 \mathrm{mg} / \mathrm{kg} /$ día) con metotrexato ( $25 \mathrm{mg}$ semanal) en mantención de remisión, demostrando iguales tasas de recaídas $(33 \%)$ y de efectos adversos.

Leflunomida. Un estudio aleatorizado multicéntrico $(2007)^{49}$, comparó leflunomida $(30 \mathrm{mg} /$ día) con metotrexato (20 mg semanal) en mantención de remisión. Las tasas de recaídas "mayores" fueron significativamente más frecuentes en el grupo metotrexato, lo que obligó a suspender el estudio, pero la tasa de efectos adversos fue mucho mayor con leflunomida.

Dado que en artritis reumatoide la combinación de metotrexato con leflunomida es efectiva, un estudio alemán evaluó 51 pacientes de una cohorte de 864 con GPA, que recibieron terapia combinada con leflunomida y metotrexato. En 43/51 pacientes la combinación indujo remisión, con 51 eventos adversos en 36 pacientes, principalmente infecciones menores.

Micofenolato mofetil. El estudio IMPROVE ${ }^{50}$ comparó micofenolato con azatioprina, para mantención de remisión. Ochenta pacientes recibieron azatioprina ( $2 \mathrm{mg} / \mathrm{kg} /$ día) y 76 Micofenolato ( $2 \mathrm{~g} /$ día), y fueron seguidos por 39 meses, analizando los resultados con intención de tratar. La tasa de recaída fue significativamente mayor con micofenolato, y la tasa de efectos adversos fue similar.

Rituximab. Los estudios con este agente para mantención de remisión están en curso. Un estudio de la Clínica Mayo, de 108 pacientes tratados con al menos un pulso de rituximab para inducción de remisión en vasculitis, fueron seguidos por 10 años $^{51}$. Cincuenta y tres requirieron subsecuentes pulsos, recibiendo una mediana de 4 pulsos. Todas las recaídas se observaron una vez reconstituidos los linfocitos, y precedidas por la elevación de título del ANCA. Treinta y cuatro por ciento de los pulsos fueron administrados por recaídas y $66 \%$ en forma "preventiva", ante la reconstitución de los linfocitos B CD20 o por la elevación de ANCA.

Hay también un estudio prospectivo en curso denominado MAINRITSAN, para comparar rituximab (500 mg cada 6 meses) vs azatioprina, para la mantención de remisión.

\section{Conclusión}

Múltiple evidencia apoya el papel de los ANCA en la patogenia de las VAA, destacando el desarrollo de modelos murinos de la enfermedad basados en los antígenos más relevantes, PR3 y MPO. En VAA de forma limitada o sistémica precoz, el metotrexato es una buena opción para conseguir remisión; en casos con compromiso pulmonar agregado o alto nivel de actividad, otras alternativas deben ser consideradas. En VAA con compromiso sistémico grave, la ciclofosfamida sigue siendo la terapia estándar para la inducción de remisión. Sin embargo, el nivel de toxicidad asociada a su uso a largo plazo, ha motivado la búsqueda de nuevas opciones terapéuticas. Rituximab es una nueva opción terapéutica con eficacia similar demostrada, cuya toxicidad a largo plazo debe evaluarse en seguimientos a largo plazo. 


\section{Referencias}

1. Falk RJ, Jennette JC. ANCA disease: where is this field heading? J Am Soc Nephrol 2010; 21 (5): 745-52.

2. Jennette JC. Nomenclature and classification of vasculitis: lessons learned from granulomatosis with polyangiitis (Wegener's granulomatosis). Clin Exp Immunol 2011; 164 Suppl 1: 7-10.

3. Vasculitis Clinical Research Consortium. Disponible en: http://rarediseasesnetwork.epi.usf.edu/vcrc/index.htm.

4. The European Vasculitis Study Group. Disponible en: http://www.vasculitis.org/.

5. French Vasculitis Study Group. Disponible en: http:// www.vascularites.org/index.php

6. Lynch JP, 3rd, E. White H. Tazelaar and C.A. Langford, Wegener's granulomatosis: evolving concepts in treatment. Semin Respir Crit Care Med 2004; 25 (5): 491-521.

7. Kallenberg CG. Pathogenesis of PR3-ANCA associated vasculitis. J Autoimmun 2008; 30 (1-2): 29-36.

8. Savage CO, Harper L, Holland M. New findings in pathogenesis of antineutrophil cytoplasm antibodyassociated vasculitis. Curr Opin Rheumatol 2002; 14 (1): 15-22.

9. Finkielman JD, Merkel PA, Schroeder D, Hoffman GS, Spiera R, St Clair EW, et al. Antiproteinase 3 antineutrophil cytoplasmic antibodies and disease activity in Wegener granulomatosis. Ann Intern Med 2007; 147 (9): 611-9.

10. Sebastian JK, Mahr AD, Ahmed SS, Stone JH, Romay-Penabad Z, Davis JC, et al. Antiendothelial cell antibodies in patients with Wegener's granulomatosis: prevalence and correlation with disease activity and manifestations. J Rheumatol 2007; 34 (5): 1027-31.

11. Kallenberg CG. Antineutrophil cytoplasmic autoantibody-associated small-vessel vasculitis. Curr Opin Rheumatol 2007; 19 (1): 17-24.

12. Choi HK, Lamprecht P, Niles JL, Gross WL, Merkel PA. Subacute bacterial endocarditis with positive cytoplasmic antineutrophil cytoplasmic antibodies and antiproteinase 3 antibodies. Arthritis Rheum 2000; 43 (1): 226-31.

13. Stegeman CA, Tervaert JW, Sluiter WJ, Manson WL, de Jong PE, Kallenberg CG. Association of chronic nasal carriage of Staphylococcus aureus and higher relapse rates in Wegener granulomatosis. Ann Intern Med 1994; 120 (1): 12-7.

14. Little MA, Smyth CL, Yadav R, Ambrose L, Cook HT, Nourshargh S, et al. Antineutrophil cytoplasm antibodies directed against myeloperoxidase augment leukocyte-microvascular interactions in vivo. Blood
2005; 106 (6): 2050-8.

15. Xiao H, Heeringa $P$, Hu P, Liu Z, Zhao M, Aratani Y, et al. Antineutrophil cytoplasmic autoantibodies specific for myeloperoxidase cause glomerulonephritis and vasculitis in mice. J Clin Invest 2002; 110 (7): 955-63.

16. Xiao H, Heeringa P, Liu Z, Huugen D, Hu P, Maeda N, et al. The role of neutrophils in the induction of glomerulonephritis by anti-myeloperoxidase antibodies. Am J Pathol 2005; 167 (1): 39-45.

17. Voswinkel J, Mueller A, Kraemer JA, Lamprecht P, Herlyn K, Holl-Ulrich K, et al. B lymphocyte maturation in Wegener's granulomatosis: a comparative analysis of $\mathrm{VH}$ genes from endonasal lesions. Ann Rheum Dis 2006; 65 (7): 859-64.

18. Popa ER, Stegeman CA, Bos NA, Kallenberg CG, Tervaert JW. Differential B- and T-cell activation in Wegener's granulomatosis. J Allergy Clin Immunol 1999; 103 (5 Pt 1): 885-94.

19. Little MA, Al-Ani B, Ren S, Al-Nuaimi H, Leite M Jr, Alpers CE, et al. Anti-proteinase 3 anti-neutrophil cytoplasm autoantibodies recapitulate systemic vasculitis in mice with a humanized immune system. PLoS One. 7 (1): e28626.

20. Flint J, Morgan MD, Savage CO. Pathogenesis of ANCAassociated vasculitis. Rheum Dis Clin North Am 2010; 36 (3): 463-77.

21. Halbwachs-Mecarelli L, Bessou G, Lesavre P, López S, Witko-Sarsat V. Bimodal distribution of proteinase 3 (PR3) surface expression reflects a constitutive heterogeneity in the polymorphonuclear neutrophil pool. FEBS Lett 1995; 374 (1): 29-33.

22. Schreiber A, Busjahn A, Luft FC, Kettritz R. Membrane expression of proteinase 3 is genetically determined. J Am Soc Nephrol 2003; 14 (1): 68-75.

23. Jennette JC, Xiao H, Falk RJ. Pathogenesis of vascular inflammation by anti-neutrophil cytoplasmic antibodies. J Am Soc Nephrol 2006; 17 (5): 1235-42.

24. Williams JM, Savage CO. Characterization of the regulation and functional consequences of $\mathrm{p} 21$ ras activation in neutrophils by antineutrophil cytoplasm antibodies. J Am Soc Nephrol 2005; 16 (1): 90-6.

25. Kettritz R, Choi M, Butt W, Rane M, Rolle S, Luft FC, et al. Phosphatidylinositol 3-kinase controls antineutrophil cytoplasmic antibodies-induced respiratory burst in human neutrophils. J Am Soc Nephrol 2002; 13 (7): 1740-9.

26. Hewins P, Williams JM, Wakelam MJ, Savage CO. Activation of Syk in neutrophils by antineutrophil cytoplasm antibodies occurs via Fcgamma receptors and CD18. J Am Soc Nephrol 2004; 15 (3): 796-808.

27. Yang JJ, Preston GA, Alcorta DA, Waga I, Munger WE, 
Hogan SL, et al. Expression profile of leukocyte genes activated by anti-neutrophil cytoplasmic autoantibodies (ANCA). Kidney Int 2002; 62 (5): 1638-49.

28. Calderwood JW, Williams JM, Morgan MD, Nash GB, Savage CO. ANCA induces beta2 integrin and CXC chemokine-dependent neutrophil-endothelial cell interactions that mimic those of highly cytokine-activated endothelium. J Leukoc Biol 2005; 77 (1): 33-43.

29. Radford DJ, Luu NT, Hewins P, Nash GB, Savage CO. Antineutrophil cytoplasmic antibodies stabilize adhesion and promote migration of flowing neutrophils on endothelial cells. Arthritis Rheum 2001; 44 (12): 285161.

30. Bacon PA. The spectrum of Wegener's granulomatosis and disease relapse. N Engl J Med 2005; 352 (4): 330-2.

31. Jayne DR, Rasmussen N. Treatment of antineutrophil cytoplasm autoantibody-associated systemic vasculitis: initiatives of the European Community Systemic Vasculitis Clinical Trials Study Group. Mayo Clin Proc 1997; 72 (8): 737-47.

32. Nachman PH, Hogan SL, Jennette JC, Falk RJ. Treatment response and relapse in antineutrophil cytoplasmic autoantibody-associated microscopic polyangiitis and glomerulonephritis. J Am Soc Nephrol 1996; 7 (1): 33-9.

33. de Groot K, Harper L, Jayne DR, Flores Suárez LF, Gregorini G, Gross WL, et al. Pulse versus daily oral cyclophosphamide for induction of remission in antineutrophil cytoplasmic antibody-associated vasculitis: a randomized trial. Ann Intern Med 2009; 150 (10): 670-80.

34. Hoffman GS, Kerr GS, Leavitt RY, Hallahan CW, Lebovics RS, Travis WD, et al. Wegener granulomatosis: an analysis of 158 patients. Ann Intern Med 1992; 116 (6): 488-98.

35. Le Guenno G, Mahr A, Pagnoux C, Dhote R, Guillevin L. Incidence and predictors of urotoxic adverse events in cyclophosphamide-treated patients with systemic necrotizing vasculitides. Arthritis Rheum 63 (5): 1435-45.

36. Hoffman GS, Leavitt RY, Kerr GS, Fauci AS. The treatment of Wegener's granulomatosis with glucocorticoids and methotrexate. Arthritis Rheum 1992; 35 (11): 1322-9.

37. De Groot K, Rasmussen N, Bacon PA, Tervaert JW, Feighery C, Gregorini G, et al. Randomized trial of cyclophosphamide versus methotrexate for induction of remission in early systemic antineutrophil cytoplasmic antibody-associated vasculitis. Arthritis Rheum 2005; 52 (8): 2461-9.

38. Jones RB, Ferraro AJ, Chaudhry AN, Brogan P, Salama $\mathrm{AD}$, Smith KG, et al. A multicenter survey of rituximab therapy for refractory antineutrophil cytoplasmic antibody-associated vasculitis. Arthritis Rheum 2009; 60 (7): 2156-68.

39. Stone JH, Merkel PA, Spiera R, Seo P, Langford CA, Hoffman GS, et al. Rituximab versus cyclophosphamide for ANCA-associated vasculitis. N Engl J Med 2010; 363 (3): 221-32.

40. Jones RB, Tervaert JW, Hauser T, Luqmani R, Morgan $\mathrm{MD}$, Peh CA, et al. Rituximab versus cyclophosphamide in ANCA-associated renal vasculitis. N Engl J Med 2010; 363 (3): 211-20.

41. Jayne DR, Gaskin G, Rasmussen N, Abramowicz D, Ferrario F, Guillevin L, et al. Randomized trial of plasma exchange or high-dosage methylprednisolone as adjunctive therapy for severe renal vasculitis. J Am Soc Nephrol 2007; 18 (7): 2180-8.

42. Etanercept plus standard therapy for Wegener's granulomatosis. N Engl J Med 2005; 352 (4): 351-61.

43. Stone JH, Holbrook JT, Marriott MA, Tibbs AK, Sejismundo LP, Min YI, et al. Solid malignancies among patients in the Wegener's Granulomatosis Etanercept Trial. Arthritis Rheum 2006; 54 (5): 1608-18.

44. Booth A, Harper L, Hammad T, Bacon P, Griffith M, Levy J, et al. Prospective study of TNFalpha blockade with infliximab in anti-neutrophil cytoplasmic antibody-associated systemic vasculitis. J Am Soc Nephrol 2004; 15 (3): 717-21.

45. Jayne D, Rasmussen N, Andrassy K, Bacon P, Tervaert JW, Dadoniene J, et al. A randomized trial of maintenance therapy for vasculitis associated with antineutrophil cytoplasmic autoantibodies. N Engl J Med 2003; 349 (1): 36-44.

46. de Groot K, Reinhold-Keller E, Tatsis E, Paulsen J, Heller M, Nolle B, et al. Therapy for the maintenance of remission in sixty-five patients with generalized Wegener's granulomatosis. Methotrexate versus trimethoprim/sulfamethoxazole. Arthritis Rheum 1996; 39 (12): 2052-61.

47. Langford CA, Talar-Williams C, Barron KS, Sneller MC. A staged approach to the treatment of Wegener's granulomatosis: induction of remission with glucocorticoids and daily cyclophosphamide switching to methotrexate for remission maintenance. Arthritis Rheum 1999; 42 (12): 2666-73.

48. Pagnoux C, Mahr A, Hamidou MA, Boffa JJ, Ruivard M, Ducroix JP, et al. Azathioprine or methotrexate maintenance for ANCA-associated vasculitis. N Engl J Med 2008; 359 (26): 2790-803.

49. Metzler C, Miehle N, Manger K, Iking-Konert C, de Groot K, Hellmich B, et al. Elevated relapse rate under oral methotrexate versus leflunomide for maintenance of remission in Wegener's granulomatosis. Rheumato- 
Vasculitis asociadas a ANCA - F. Silva et al

logy (Oxford) 2007; 46 (7): 1087-91.

50. Hiemstra TF, Walsh M, Mahr A, Savage CO, de Groot K, Harper L, et al. Mycophenolate mofetil vs azathioprine for remission maintenance in antineutrophil cytoplasmic antibody-associated vasculitis: a randomized controlled trial. Jama 2003; 304 (21): 2381-8.
51. Cartin-Ceba R, Golbin J, Keogh K, Peikert T, Fervenza F, Ytterberg S, et al. Rituximab for Remision Induction and Maintenance in ANCA-Associated Vasculitis: A Single-Center Ten Year Experience in 108 patients Arthritis \& Rheumatism 2010; 62 (Supplement 10): S 283. 